\title{
Tutupan Terumbu Karang pada Kedalaman Berbeda di Perairan Pantai Batu Sungu, Desa Les, Kabupaten Buleleng
}

\author{
I Putu Dede Charles Dharma Saputra ${ }^{\mathrm{a}}$, IGB. Sila Dharma ${ }^{\mathrm{a}}$, Yulianto Suteja ${ }^{\mathrm{a}}$, $_{\text {Widiastuti }}{ }^{*}$
}

${ }^{a}$ Prodi Ilmu Kelautan Fakultas Kelautan dan Perikanan, Universitas Udayana, Bali, Indonesia
${ }^{*}$ Corresponding author, email: widiastutikarim@unud.ac.id

\section{ARTICLE INFO}

Article history:

Received: August $11^{\text {th }} 2020$

Received in revised form: March 23 2021

Accepted: June $21^{\text {th }} 2021$

Available online: August $31^{\text {th }} 2021$

Keywords:

Batu Sungu Beach

Coral Coverage

Line Intercept Transect

T Test

\section{ABSTRACT}

Bali island has many magnificent underwater coral reef gardens that attract tourists. Besides Pemuteran and Menjangan island waters, Batu Sungu water has also potential to be a new tourist destination. Thus, to determine the potency and management plan in Batu Sungu waters, this research aimed to examine the overall coral cover, coral growth forms, other benthic forms, and each of their components in 5 and $10 \mathrm{~m}$ depths. The overall coral cover, coral growth forms, other benthic forms, and each of their components were counted by using the Line Intercept Transect (LIT) method. Before collecting data, study sites were observed by using the Manta Tow method. Data were collected in 2 depths ( 5 dan $10 \mathrm{~m}$ ) with 5 sites each (replicates) that separates within 50 to $150 \mathrm{~m}$. A $25 \mathrm{~m}$ LIT was spread parallel to the coastline above the reefs. Live coral colonies, other benthic forms below the transects were measured for the number, length, and growth forms. Water quality was measured in situ (temperature, current, and clarity) and ex situ $(\mathrm{pH})$. Results showed that the category of coral coverage in Batu Sungu water is "good" in $5 \mathrm{~m}$ and "moderate" in $10 \mathrm{~m}$ whereas there was no significant difference among each component of the overall coral cover. The most dominant coral growth form among the 2 depths was Coral Massive whereas significantly abundant in $5 \mathrm{~m}$. Moreover, the number of Coral Foliose was found significantly high in the same depth. Other coral growth forms were relatively similar in numbers in two depths. As likewise, the cover of other benthic forms and its component were not significantly different among two depths, except Dead Coral with Algae which significantly plentiful in $5 \mathrm{~m}$. Sand was dominantly found in two depths with no significant difference. Furthermore, Coraline Alga was only observed in $5 \mathrm{~m}$, however, there were no Macroalga and Alga Assemblages found at this depth. It is assumed that the similarity number of the overall coral cover, coral growth forms, other benthic forms, and each of their components is related to the alikeness of water quality among the two depths. 


\section{Pendahuluan}

Penelitian dan pemantauan terumbu karang terhadap 1067 site di seluruh Indonesia yang diadakan Lembaga Ilmu Pengetahuan Indonesia (LIPI) melalui Pusat Penelitian Oseanografi (P2O) menunjukkan bahwa terumbu karang dalam kategori buruk sebanyak 386 site (36.18\%), kategori cukup sebanyak 366 site (34.3\%), kategori baik sebanyak 245 site $(22.96 \%)$ dan kategori sangat baik sebesar 70 site $(6.56 \%)$ (Hadi et al, 2018). Secara umum, terumbu karang dalam kategori baik dan cukup mengalami tren penurunan, namun sebaliknya kategori sangat baik dan jelek mengalami peningkatan apabila dibandingkan dengan tahun sebelumnya (Hadi et al, 2018).

Meningkatnya persentase terumbu karang kategori jelek bisa disebabkan oleh faktor alami atau faktor akibat aktifitas manusia. Faktor alami yaitu perubahan iklim yang mengakibatkan coral bleaching (pemutihan karang), beberapa hewan yang memakan polip karang atau biota yang membuat sarang diantara atau didalam koloni karang seperti Parrot fish dan Bintang Laut Mahkota Duri (Acanthaster planci) serta beberapa penyakit karang seperti Black Disease dan White Disease. Sedangkan Faktor akibat aktifitas manusia yaitu antara lain pencemaran, eutrofikasi, serta pengambilan karang yang berlebih dan merusak (Hadi et al., 2018).

Pulau Bali memiliki berbagai wisata terumbu karang yang menarik kunjungan wisatawan. Selain di Pemuteran dan Pulau menjangan, titik terumbu karang yang ada di Pulau Bali juga terdapat di Perairan Pantai Batu Sungu (Prasetia, 2018). Perairan ini merupakan salah satu pantai yang terletak di Desa Les, Kecamatan Tejakula yang berada di wilayah paling timur Kabupaten Buleleng (Prasetia, 2018). Dalam rangka mengetahui potensi dan pengelolaan ekosistem terumbu karang di Perairan Pantai Batu Sungu atau yang biasa disebut juga dengan Pantai Les maka penelitian bertujuan untuk mengetahui Persentase Tutupan Karang, bentuk pertumbuhan karang hidup dan tutupan bentos lainnya serta masing-masing komponen penyusunnya pada kedalaman 5 dan $10 \mathrm{~m}$ di Perairan Pantai Batu Sungu.

\section{Metode}

\subsection{Waktu dan Tempat Penelitian}

Pengambilan data persentase tutupan terumbu karang dan kualitas perairan dilaksanakan pada bulan Juni 2018 di Perairan Pantai Batu Sungu, Kecamatan Tejakula, Kabupaten Buleleng. Perairan Pantai Batu Sungu merupakan pantai yang berbatu yang memiliki panjang pantai sepanjang $562 \mathrm{~m}$ dimana batas timur nya berada di kordinat $8^{\circ} 7,865^{\prime} \mathrm{LS}-115^{\circ} 22,179^{\prime} \mathrm{BT}$ dan batas barat nya berada di kordinat $8^{\circ} 7,780$ 'LS $-115^{\circ} 22,019^{\prime} \mathrm{BT}$

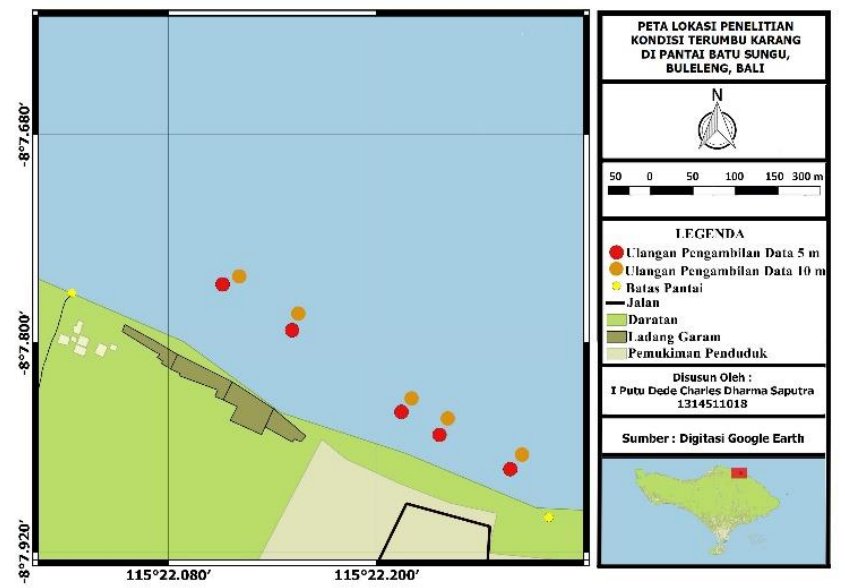

Gambar 1. Peta lokasi penelitian kondisi terumbu karang di Pantai Batu Sungu, Buleleng, Bali)

\subsection{Metode Pengambilan Data \\ 2.2.1 Persentase Tutupan Karang}

Pengambilan data persentase tutupan terumbu karang menggunakan metode LIT (Line Intercept Transect) menurut English et al (1994). Sebelum dilakukan pengambilan data, terlebih dulu menentukan lokasi pengamatan dengan teknik observasi Manta Tow (Rinduwati et al, 2015) menggunakan Scuba set. Pengambilan data persentase tutupan terumbu karang dilakukan dengan memilih 2 kedalaman yang berbeda yaitu 5 dan $10 \mathrm{~m}$ dimana pada masingmasing kedalaman memiliki 5 transek yang dihitung sebagai pengulangan. Masing-masing titik pengulangan berjarak antara 50 sampai $150 \mathrm{~m}$. Garis transek dibentangkan sepanjang $25 \mathrm{~m}$ sejajar dengan garis pantai diatas terumbu karang.

Koloni karang hidup, bentuk pertumbuhan dan bentik lainnya yang terletak di bawah garis transek diukur panjang, bentuk pertumbuhannya dan dihitung jumlahnya berdasarkan pada lifeform pertumbuhan karang (English et al., 1994).

\subsubsection{Kualitas Perairan}

Pengukuran faktor fisik-kimia perairan dilakukan dengan cara pengukuran langsung di lokasi pengamatan (suhu, arus dan kecerahan) dan mengambil sampel air, dimasukan ke dalam botol yang telah diberikan label kemudian diukur di darat $(\mathrm{pH})$.

\subsection{Analisis Data}

\subsubsection{Persentase Tutupan Karang}

Data persentase tutupan karang yang didapat kemudian dianalisa untuk mengetahui kondisi terumbu karang yang ada yaitu dengan cara menghitung persen tutupan dan tingkat kematian karang menggunakan metode persamaan English et al (1997). Persen tutupan karang yang telah dihitung kemudian dicocokan dengan Indeks kriteria persen tutupan karang menurut Gomez dan Yap (1998). Persentase penutupan karang dihitung menggunakan persamaan 1 (English et al. 1997).

Persentase tutupan karang $=\frac{\text { Panjang Tutupan }(\mathrm{cm})}{\text { Panjang Transek }(\mathrm{cm})} \times 100 \%$

Kategori persetase tutupan karang hidup dihitung berdasarkan Gomez dan Yap (1998) yang ditunjukkan pada Tabel 1 .

Tabel 1. Kriteria persentase tutupan karang hidup

\begin{tabular}{cc}
\hline $\begin{array}{c}\text { Presentase } \\
\text { Penutupan }\end{array}$ & Kriteria Penilaian \\
\hline $0-24.9 \%$ & Buruk \\
$25-49.9 \%$ & Sedang \\
$50-74.9 \%$ & Baik \\
$75-100 \%$ & Sangat Baik \\
\hline
\end{tabular}

\subsubsection{Kualitas Air}

\section{a. Kecerahan}

Data kecerahan yang telah didapat kemudian dihitung dengan menggunakan persamaan kecerahan menurut standard Badan Standarisasi Nasional (1991)

$$
\text { Kecerahan }=\frac{\operatorname{Jarak} \text { Hilang }(\mathrm{m})+\operatorname{Jarak} \operatorname{Tampak}(\mathrm{m})}{2} \times 100 \%
$$

Dimana jarak hilang (m) adalah jarak pertama Secchi disk menghilang pada saat diturunkan, dan jarak tampak (m) adalah jarak pertama saat secchi disk tampak pada saat dinaikan. 


\section{b. Kecepatan Arus}

Data kecepatan arus yang telah diukur dilapangan kemudian dimasukan kedalam persamaan 3 menurut Triatmodjo (1999) :

$$
V=S / t
$$

Dimana $V$ merupakan kecepatan arus $(\mathrm{m} / \mathrm{s}), S$ adalah jarak tali menegang $(\mathrm{m} / \mathrm{s})$ dan $t$ adalah waktu tali menegang. Setelah itu nilai kecepatan arus yang didapat kemudian dicocokan dengan skala kecepatan arus menurut Mason (1981) (Tabel 2).

Tabel 2. Skala kecepatan arus menurut Mason (1981)

\begin{tabular}{cc}
\hline Skala $(\mathbf{c m} / \mathbf{s})$ & Keterangan \\
\hline$>100$ & Sangat Cepat \\
$51-100$ & Cepat \\
$25-50$ & Sedang \\
$<10$ & Lambat \\
\hline
\end{tabular}

\subsection{Analisa Statistik}

Perbedaan persentase tutupan karang, bentuk pertumbuhan karang hidup dan tutupan bentos lainnya serta masing-masing komponen penyusunnya pada kedalaman 5 dan $10 \mathrm{~m}$ di Perairan Pantai Batu Sungu dianalisa dengan uji t bebas. Sebelum dilakukan uji tersebut, terlebih dahulu dilakukan uji normalitas untuk mengetahui distribusi data pada masingmasing komponen. Apabila data tidak terdistribusi normal, maka dilakukan transformasi data dan kembali dilakukan uji normalitas, dan jika data masih tidak berdistribusi normal maka dilakukan uji analisa non parametrik Mann Whitney. Analisa statistic dilakukan dengan menggunakan software trial SPSS versi 25 .

\section{Hasil dan Pembahasan}

\subsection{Parameter Kualitas Perairan}

Berdasarkan pengamatan visual diperoleh bahwa umumnya substrat perairan Pantai Batu Sungu yaitu berbatu dan berpasir hitam serta memiliki formasi terumbu karang yang dapat dijumpai pada kedalaman $5 \mathrm{~m}$ hingga $10 \mathrm{~m}$. Pertumbuhan terumbu karang dipengaruhi oleh berbagai faktor fisika dan kimia perairan. Pengambilan data parameter kualitas perairan di masing-masing kedalaman dilakukan pada hari yang bersamaan. Data parameter kualitas perairan disajikan pada Tabel 3.

Tabel 3. Data rata-rata (mean \pm stdev) pengukuran parameter kualitas fisika dan kimia perairan di Pantai Batu Sungu

\begin{tabular}{|c|c|c|c|}
\hline Parameter & $5 \mathrm{~m}$ & $10 \mathrm{~m}$ & $\begin{array}{c}\text { KEPMEN LH } \\
\text { No } 51 \text { tahun } \\
2004\end{array}$ \\
\hline Suhu $\left({ }^{\circ} \mathrm{C}\right)$ & $\begin{array}{c}30.02 \pm \\
0.14\end{array}$ & $29.68 \pm 0.38$ & $28-30{ }^{\circ} \mathrm{C}$ \\
\hline $\begin{array}{c}\text { Salinitas } \\
(\%)\end{array}$ & $\begin{array}{c}32.92 \pm \\
0.10\end{array}$ & $32.76 \pm 0.33$ & $33-34 \%$ \\
\hline
\end{tabular}

\begin{tabular}{cccc}
\hline $\mathrm{pH}$ & $8.12 \pm 0.08$ & $8.08 \pm 0.10$ & $7-8.5$ \\
$\begin{array}{c}\text { Kecerahan } \\
(\%)\end{array}$ & $100 \pm 2.12$ & $95 \pm 4.26$ & $>5 \mathrm{~m}$ \\
$\begin{array}{c}\text { Arus } \\
(\mathrm{m} / \text { detik })\end{array}$ & $0.38 \pm 0.08$ & $0.38 \pm 0.08$ & - \\
\hline
\end{tabular}

Berdasarkan Tabel 3, secara umum seluruh parameter fisika kimia perairan pada kedua kedalaman memiliki nilai yang relatif sama. Nilai suhu, salinitas dan $\mathrm{pH}$ pada masing-masing kedalaman berada pada kisaran nilai yang baik dan optimal untuk kehidupan serta pertumbuhan karang (KEPMEN LH. 2004). Nilai kecepatan arus pada kedua kedalaman jika dibandingkan dengan tabel kecepatan arus milik Mason (1981) menunjukkan, nilai yang sama yaitu kategori "sedang". Pengambilan data kecepatan arus dilakukan pada saat pagi menjelang siang hari dimana pada saat itu air laut sedang mengalami proses surut menuju pasang.

\subsection{Persentase Tutupan Karang}

Berdasarkan kategori penilaian kondisi ekosistem terumbu karang oleh Gomez and Yap (1988), maka persentase tutupan terumbu karang di Perairan Pantai Batu Sungu seperti yang terlihat pada Tabel 4.

Tabel 4. Data Rata-rata Persentase Tutupan Karang (rata-rata \pm stdev) di kedalaman 5 dan $10 \mathrm{~m}$ pada masing-masing komponen persen tutupan karang.

\begin{tabular}{|c|c|c|c|}
\hline \multirow{2}{*}{ Komponen } & \multicolumn{2}{|c|}{$\begin{array}{c}\text { Rata-rata Persentase Tutupan } \\
(\%)\end{array}$} & \multirow{2}{*}{$\begin{array}{c}\text { Tingkat } \\
\text { Signifikansi }(P \text { - } \\
\text { values })\end{array}$} \\
\hline & $5 \mathrm{~m}$ & $10 \mathrm{~m}$ & \\
\hline $\begin{array}{l}\text { Karang } \\
\text { Hidup }\end{array}$ & $51.72 \pm 13.55$ & $\begin{array}{c}38.27 \pm \\
23.14\end{array}$ & 0.295 \\
\hline Karang Mati & $9.23 \pm 3.46$ & $6.2 \pm 2.09$ & 0.140 \\
\hline Biota Lain & $5.42 \pm 1.64$ & $5.79 \pm 3.1$ & 0.827 \\
\hline Alga & $5.37 \pm 2.40$ & $4.31 \pm 2.19$ & 0.486 \\
\hline Abiotik & $28.24 \pm 12.82$ & $45.42 \pm 27.83$ & 0.245 \\
\hline Total & $100 \%$ & $100 \%$ & \\
\hline
\end{tabular}

Berdasarkan hasil uji t bebas pada masing-masing komponen persen tutupan karang di kedua kedalaman diketahui bahwa tidak ada perbedaan signifikan antara persen tutupan karang hidup, karang mati, biota lain, alga dan abiotik (Tabel 4). Namun, tingginya persen tutupan karang mati di kedalaman 5 m daripada 10 $\mathrm{m}$ dapat disebabkan persen tutupan alga yang lebih tinggi di kedalaman $5 \mathrm{~m}$ daripada $10 \mathrm{~m}$. Jenis alga yang ditemukan pada kedua kedalaman umumnya yaitu jenis turf algae yang menempel di karang.

Pada penelitian Dianastuty (2016) mengenai kompetisi karang dengan turf algae menunjukan bahwa terjadi suatu kompetisi dengan pertumbuhan turf algae yang mengalami ekspansi terhadap karang hidup, dimana dalam 122 hari panjang turf alga mengalami peningkatan sepanjang $3.42 \mathrm{~cm}$. Apabila hal tersebut berlangsung terus menerus maka dimungkinkan karang tidak dapat recovery dan mati. 
Menurut Afni (2017) Persentase penutupan karang yang telah ditumbuhi alga lebih besar dapat memicu pertumbuhan alga yang sangat pesat dapat menghambat pertumbuhan karang keras.

Walaupun persentase tutupan karang hidup pada kedua kedalaman tidak berbeda signifikan, tetapi nilai persentase tutupan karang hidup di kedalaman $10 \mathrm{~m}$ lebih rendah dibandingkan $5 \mathrm{~m}$. Hal ini dapat dikarenakan pada kedalaman $10 \mathrm{~m}$ kategori pasir (Abiotik) lebih tinggi daripada di $5 \mathrm{~m}$ (Tabel 4).

Menurut Penelitian Richmond (1977) dalam Rudi et al (2005) menyatakan bahwa planula tidak akan menempel pada sedimen yang longgar dan tidak cocok, seperti substrat pasir, Kalaupun penempelan terjadi, kelulus hidupan akan rendah. Tetapi perbedaan tutupan kategori pasir tersebut tidak menunjukkan nilai yang signifikan antar kedalaman. Tingginya persen tutupan alga pada karang mati pada kedalaman $5 \mathrm{~m}$ dapat berhubungan dengan lebih tinggi persennya tutupan karang mati di kedalaman ini, tetapi perbedaan komponen tutupan alga dan karang mati tersebut tidak menunjukkan nilai yang signifikan antar kedalaman.

Persentase tutupan biota lain pada kedua kedalaman tidak menunjukkan perbedaan yang signifikan (Tabel 4). Soft coral atau yang biasa disebut Karang Lunak merupakan biota lain selain karang keras yang mendominasi kedua kedalaman. Rendahnya nilai tutupan karang lunak pada kedua kedalaman dibandingkan tutupan karang hidup sesuai dengan Delanov (2012) bahwa karang lunak akan mengalami stress karena kompetisi dalam memperebutkan ruang dan makanan dengan karang keras maupun alga.

Perbedaan bentuk pertumbuhan karang hidup dan komponen persen tutupan karang Hidup lainnya di kedalaman 5 dan 10 m ditunjukkan pada Gambar 3.

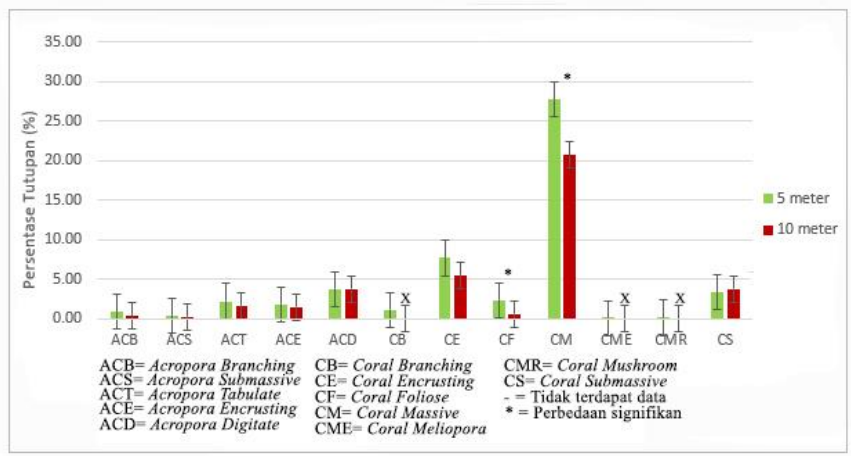

Gambar 3. Rata-rata persentase tutupan karang berdasarkan bentuk pertumbuhan karang hidup dan Komponen Persen Tutupan Karang Hidup Lainnya di kedalaman 5 dan 10 m.

Berdasarkan Gambar 3, secara umum tutupan karang berdasarkan bentuk pertumbuhan karang hidup dan komponen penyusunnya di Perairan Pantai Batu Sungu di kedua kedalaman tidak berbeda signifikan, kecuali bentuk pertumbuhan Coral Massive (CM) dan Coral Foliose (CF). Bedasarkan hasil uji t, Coral Massive (CM) dan Coral Foliose (CF) secara signifikan melimpah di kedalaman $5 \mathrm{~m}$.

Menurut penelitian Li et al (2011) mengatakan, terumbuu karang Massive dan Foliose mempunyai daya tahan dan adaptasi tinggi terhadap perubahan lingkungan sekitar. Penelitian Muzaki et al, dalam Amrillah et al (2019) menjelaskan bentuk karang Foliose yang pipih seperti daun dan melebar seperti payung memungkinkan Zooxanthellae dapat menyerap maksimal cahaya matahari untuk proses fotosintesis. Menurut Nababan (2009), Coral Massive mempunyai daya kompetisi yang tinggi, dengan harapan hidup yang panjang. Coral Branching (CB), Coral Meliopora (CME), Coral Mushroom (CMR) hanya di dijumpai pada kedalaman $5 \mathrm{~m}$ saja, hal tersebut diduga karena pada kedalaman 10 didominasi oleh subtract pasir (S), Studi Harrison dan Wallace (1990) menunjukkan bahwa larva karang lebih menyukai media keras untuk tempatnya menempel. Menurut Lutfi (2017), secara alami karang keras akan sulit tumbuh di kawasan yang didominasi oleh pasir karena substrat pasir mudah teraduk oleh arus atau gelombang.

Hal tersebut menjadi dugaan mengapa karang Coral Massive (CM) dan Coral Foliose (CF) secara signifikan melimpah pada kedalaman $5 \mathrm{~m}$.

Rata-rata persentase tutupan bentik dan komponen penyusunnya di kedalaman $5 \mathrm{~m}$ dan $10 \mathrm{~m}$ ditunjukkan Gambar 4 . Komponen yang dominan pada kategori ini yaitu pasir (Sand), namun tidak berbeda pada kedua kedalaman. Dead Coral with Algae (DCA) merupakan komponen dominan kedua dimana menurut Hasil uji $\mathrm{t}$ bebas jumlahnya lebih banyak secara signifikan di kedalaman $5 \mathrm{~m}$ daripada di $10 \mathrm{~m}$. Coraline alga (CA) hanya ditemukan di kedalaman 5 m, sedangkan Macroalga (MA) dan Alga assemblages (AA). Komponen lainnya ditemukan pada kedua kedalaman, tetapi jumlahnya tidak berbeda secara signifikan antar kedua kedalaman.

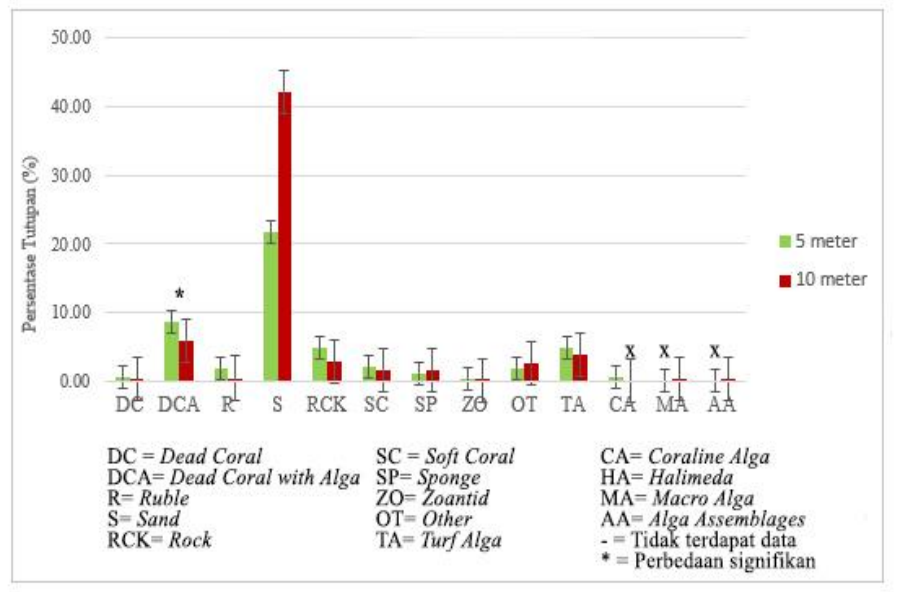

Gambar 4. Rata-rata persentase kategori tutupan karang mati, biota lain, abiotik dan algae di kedalaman $5 \mathrm{~m}$ dan $10 \mathrm{~m}$.

Tidak adanya perbedaan signifikan antar masing-masing komponen penyusun tutupan karang. Bentuk pertumbuhan karang hidup dan persentase tutupan bentik serta masing-masing komponen penyusunnya diduga karena kualitas fisika dan kimia perairan yang ada pada kedua kedalaman menunjukan nilai yang relatif tidak jauh berbeda dimana semua parameter berada pada kategori baik menurut KEPMEN LH No 51 tahun 2004 untuk baku mutu perairan.

\section{Kesimpulan}

Persentase Tutupan Karang di Perairan Batu Sungu berada pada kategori "Baik" di kedalaman 5 m dan "Sedang" di kedalaman $10 \mathrm{~m}$ dimana tidak ada perbedaan signifikan antar komponen penyusun tutupan karang. Bentuk pertumbuhan karang hidup yang paling dominan di kedua kedalaman yaitu Coral Massive (CM) yang secara signifikan melimpah di kedalaman $5 \mathrm{~m}$.

Selain itu, CM, Coral Foliose (CF) merupakan bentuk pertumbuhan karang hidup yang secara signifikan lebih tinggi di kedalaman $5 \mathrm{~m}$.

Persentase tutupan bentik dan Komponen penyusunnya umumnya tidak berbeda signifikan di kedua kedalaman, kecuali Dead Coral with Algae (DCA) yang jumlahnya lebih banyak secara signifikan di kedalaman $5 \mathrm{~m}$ daripada di $10 \mathrm{~m}$. pasir (Sand), merupakan komponen dominan tetapi persen tutupannya tidak berbeda signifikan antar kedalaman. Coraline alga (CA) hanya ditemukan di kedalaman 5 m, sedangkan Macroalga (MA) dan Alga assemblages (AA) tidak dijumpai pada kedalaman $5 \mathrm{~m}$. 


\section{JMRT, Volume 4 No 2 Tahun 2021, Halaman: 42-46}

\section{Ucapan Terima kasih}

Penulis mengucapkan terima kasih kepada dosen pembimbing dan seluruh pihak yang turut membantu penulis dalam pengambilan data dan penulisan, yang tidak bisa di cantumkan satu persatu

\section{Daftar Pustaka}

Afni N. 2017. Kondisi terumbu karang di Pulau Samatellu Pedda Kecamatan Liukang Tupabbiring Kabupaten Pangkep Sulawesi Selatan [skripsi]. Makasar: Fakultas Sains dan Teknologi UIN Alauddin Makassar. 102 hal.

Amrillah K, Adi W, Kurniawan. 2019. Pemetaan sebaran terumbu karang di Perairan Pulau Kelapan, Kabupaten Bangka Selatan berdasarkan data satelit sentinel 2a. Journal of Tropical Marine Science Vol. 2 Tahun 2019 Halaman: 59-70.

Badan Standarisasi Nasional. 1991. SNI.06-2412-1991. Metode Pengambilan Contoh Kualitas Air.

Delanov AA. 2012. Laju pertumbuhan dan kesehatan soft coral sinularia dura hasil transplantasi pada sistem resirkulasi [Skripsi] Bogor : Departemen Ilmu Dan Teknologi Kelautan Fakultas Perikanan Dan Ilmu Kelautan Institut Pertanian Bogor. 59 hal.

Dianastuty EH, Trianto A, Sedjati S. 2016. Studi Kompetisi Turf Algae Dan Karang Genus Acropora Di Pulau Menjangan Kecil, Kepulauan Karimunjawa, Kabupaten Jepara. Prosding Seminar Nasional Tahunan ke - V Hasil Penelitian Perikanan dan Kelautan; Semarang, 2016. Halaman 600-608.

English, S., C. Wilkinson dan V. Baker. 1994. Survey Manual for Tropical Marine Recourses. Australian Institut of Marine Science. Townsville. hlm: 34-80.

English SC, Wilkinson and V Baker, 1997. Survey Manual for Tropical Marine Resources. Second Edition. Australia Institute of Marine Science.Townsville: 390 p

Gomez ED, Yap HT. 1998. Monitoring Reef Condition. in Kenchington $R$ $A$ and Hudson B E T (ed). Coral Reef Management Hand Book. UNESCO Regional Office for Science and Technology for South East Asia. Jakarta.

Hadi TA, Giyanto, Prayudha B, Hafizt M, Budiyanto A, Suharsono. 2018 Status Terumbu Karang Indonesia 2018. Jakarta : Puslit Oseanografi - LIPI. Viii + $26 \mathrm{hlm}$

Harrison PL, Wallace CC. 1990. Reproduction, dispersal and recruitmen of Scleractinian corals. In: Dubinsky (ed.), Ecosystem of the world, coral reef. Amsterdam: Elsevier Science.

Keputusan Menteri Negara Lingkungan Hidup RI Nomor 51 Tahun 2004 Tentang Baku Mutu Air Laut. Jakarta.

Li, S., Yu, K.F., Chen, T.R., Shi, Q., Zhang, H.L. 2011. Assessment of Coral Bleaching Using Symbiotic Zooxanthellae Density and Satellite Remote Sensing Data in The Nansha Islands, South China Sea. Chinese Science Bulletin 56 (10): 1031- 1037.

Luthfi OM, Prima TA. 2017. Distribusi karang keras (Scleractinia) sebagai penyusun utama ekosistem terumbu karang di Gosong Karang Pakiman, Pulau Bawean. Jurnal Depik, Vol 6, no. 1: 9-22.

Mason CF. 1981. Biology of freshwater pollution. London: Longman Group Limited. $250 \mathrm{p}$

Nababan TM. 2009. Persen Tutupan (Percent Cover) Terumbu Karang Hidup Di Bagian Timur Perairan Pulau Rubiah Nanggroe Aceh Darussalam [Skripsi]. Medan : Departemen Biologi Fakultas Matematika Dan Ilmu Pengetahuan Alam Universitas Sumatera Utara Medan. 69 hal.

Prasetia D. 2013. Studi Identifikasi Dan Kelimpahan Ikan Karang Di Kecamatan Tejakula, Singaraja, Bali. Penelitian Masalah Lingkungan di Indonesia. Halaman 197-205.
Rinduwati R, Lapon Y, Prabuning D, Simarangkir RO, Putra MIH , Fajariyanto Y, Purwanto. 2015. Standar Operasional Prosedur Monitoring Kesehatan Terumbu Karang Taman Nasional Perairan Laut Sawu. Nusa Tenggara Timur : Balai Kawasan Konservasi Perairan Nasional Kupang. HIm 27.

Rudi E, Soedharma D, Sanusi HS, Pariwono JI. 2005. Affinitas penempelan larva karang (Scleractinia) pada substrat keras. Jurnal Ilmu-ilmu Perairan dan Perikanan Indonesia Jilid 12 No 2: $129-137$.

Triatmodjo, B. 1999. Teknik Pantai. Beta Ofset.Yogyakarta 